\title{
COLUMELA Y EL PODER FERTILIZANTE DEL ALTRAMUZ (NUEVA LECTURA DE RR 3,11,4)
}

\section{COLUMELLA 3.11.4 ON LUPIN'S VIRTUE}

\author{
José-Ignacio García Armendáriz* \\ Universidad de Barcelona
}

\begin{abstract}
RESUMEN. Defendemos la necesidad de enmendar el texto en $R R$ 3,11,4 — sustituyendo sicco fimo por succiso lupino- basándonos en la gran importancia que Columela otorga al altramuz en verde como abono, en particular para el suelo de viñas empobrecidas. Complementariamente, consideramos la conveniencia de completar el texto con propuestas como quam recentissimo <fimo> stercorari o, preferiblemente, quam recentissimo stercore $<$ spargi $>$. En nuestra pretensión de dar coherencia y sentido al conjunto del pasaje, valoramos los usos sintácticos y léxicos de Columela, así como los testimonios de autores como Varrón, Plinio o Paladio.
\end{abstract}

PALABRAS CLAVE: Crítica textual. Columela. Varrón. Paladio. Historia de la agronomía.

ABSTRACT. The paper puts forward a new conjecture for Columella 3.11.4, a locus criticus where Res rustica deals with the possibility of replanting an old vineyard. We defend that our agronomist commends there cut lupin (succisum lupinum) as a powerful dung, in order to recover the soil fertility. We also propose quam recentissimo <fimo $>$ stercorari or, preferably, quam recentissimo stercore <spargi> as a convenient complementary text. Linguistic uses of Columella, as well as passages of other authors (Varro, Pliny the Elder, Palladius...) matching the new meaning and words in 3.11.4, are adduced.

KEYWORDS: Textual criticism. Columella. Varro. Palladius. Agronomic History.

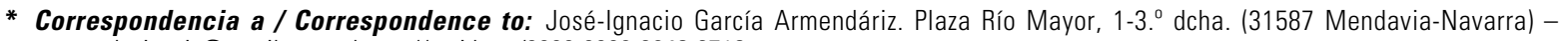
mendaviensis@gmail.com - https://orcid.org/0000-0002-3248-3719.

Cómo citar / How to cite: García Armendáriz, J.-I. (2019), "Columela y el poder fertilizante del altramuz (nueva lectura de RR 3,11,4)», Veleia, 36, 213-228. (https://doi.org/10.1387/veleia.20287).
}

Recibido: 14 octubre 2018; aceptado: 23 enero 2019.

ISSN 0213-2095 - elSSN 2444-3565 / (C) 2019 UPV/EHU 


\section{LA CUESTIÓN DEL SICCUM FIMUM}

Antes de la edición oxoniense de la Res rustica, obra de R. H. Rodgers ${ }^{1}$, quienes venimos ocupándonos de Columela nos ateníamos a la upsaliense de Lundström, Josephson y Hedberg, publicada en fascículos a lo largo de unos setenta años, de 1896 a 1968, y de méritos conocidos, especialmente en lo relativo a la exhaustiva recensio de los manuscritos. A pesar del encomiable trabajo de los filólogos suecos, subsistían en el texto bastantes corruptelas que esperaban la mano sanadora del nuevo editor. Muchas de ellas han encontrado ahora renovada lectura, si no siempre satisfactoria, planteada al menos con mayor precisión y acopio de puntos de vista. Por ello, no es de extranar que tanto el texto establecido por Rodgers como su estimulante aparato crítico hayan movido a quien esto escribe, y a cuantos se han interesado por el tratado columeliano, a reconsiderar y modificar no pocos pasajes ${ }^{2}$. El locus que motiva estas páginas $(3,11,4)$ se encuentra dentro de la viticultura y trata de la peor opción, según Columela, a la hora de elegir lugar para poner una viña, a saber, la de replantarla en el mismo terreno (restibilis uinea). Si no hay otra posibilidad — dice nuestro agrónomo- que volver a poner la viña en el sitio donde la tenemos, habrá que seguir determinadas recomendaciones para lograr que el suelo sea fértil. He aquí el texto de Upsala y nuestra traducción ${ }^{3}$ :

Vltima est, ut dixi, conditio restibilis uineae; nam si necessitas facere cogit, prius, quidquid est residuae uitis extirpari debet, deinde totum solum sicco fimo aut, si id non sit, alterius generis quam recentissimo stercorari atque ita conuerti et diligentissime refossae omnes radices in summum regeri atque comburi, tum rursus uel stercore uetusto, quia non gignit herbas, uel de uepribus egesta humo pastinatum large contegi.

«La última opción es, como he dicho, la de renovar una viña vieja. Pues, si no hay más remedio, tenemos que extirpar primero cualquier resto de cepas, y estercolar luego el terreno con fiemo seco o, si no se dispone de este, con otro tipo de fiemo lo más reciente posible, y entonces revolverlo, y volver a poner arriba todas las raíces desenterradas sin dejarse una, y quemarlas; hecho esto, hay que volver a cubrir generosamente el terreno desfondado, sea con estiércol ańejo (porque no cría hierbas) sea con mantillo traído de los zarzales».

En nota, se intentaba explicar en qué podía consistir ese siccum fimum, pues el consejo de «estercolar con fiemo seco o, en su defecto, con otro tipo de fiemo lo más reciente posible» resulta extraño. No se ve bien la diferencia de calidad y prelación que pueda haber entre el fiemo seco (primera opción) y el «de otro tipo, lo más reciente posible» —alterius generis quam recentissimo(segunda opción). Este segundo estiércol se califica doblemente: debe ser muy fresco y «de otra clase», esto es, distinto del anterior, del que solo sabemos que es seco. ¿Quiere decir Columela que el segundo no debe estar seco? Resultaría superfluo, porque ningún fiemo recentísimo es o está seco. ¿Acaso la expresión «fiemo seco» designa — como algunos pensamos en su día- un tipo particular de estiércol? Para intentar responder a estas preguntas, el recurso más inmediato es ver qué

1 Rodgers 2010. En adelante, nos referimos a la obra como $R R$. Nuestro agradecimiento a los informantes, cuyas observaciones han contribuido a mejorar estas páginas.

2 Véase García Armendáriz 2011, Lucarini 2014, Ortoleva 2006, 2012 y 2017.
3 Hedberg 1968, 43 (en redonda las dos palabras que dan pie a la discusión) y García Armendáriz 2004, 276. Hemos traducido atque comburi ("y quemarlas»), que falta en el libro. Los fragmentos de la $R R$ que se citan traducidos en estas páginas son siempre de autoría propia (publicados en ese volumen de la Biblioteca Clásica Gredos o inéditos). 
puede decirnos al respecto el propio tratado columeliano. Por varios pasajes de la $R R$, sabemos que el estercolero debe mantenerse con humedad constante. Así, en 1,6,22:

«Ya que es de la mayor importancia que el fiemo, no habiéndosele secado el jugo, retenga su fuerza y se macere con la continuada humedad a fin de que las semillas de zarzas o de heno que hayan podido entreverarse en la cama de los animales o entre la paja mueran y no transformen, llevadas al campo, las mieses en herbazales. Es por eso por lo que los campesinos experimentados cubren con ramas superpuestas todo lo que han sacado limpiando corrales de ovejas y establos, no permitiendo que el poder del sol lo seque o abrase.» (García Armendáriz 2004, 158)

Véase, en igual sentido, 2,14,7-8, donde se recomienda echarle «agua abundante y con frecuencia, para que se pudran las semillas» (García Armendáriz 2004, 221). En cuanto a 7,5,8, Columela explica ahí cómo preparar un remedio contra la sarna de las ovejas: una determinada cantidad de jugo de cicuta mezclado con sal se pone en una vasija de barro que, bien tapada, se entierra en un estercolero; se deja en él durante un año y se saca, para usarlo, cuando el medicamento está ya "cocido por el vapor del fiemo» (fimi uapore concoctum), lo que sin duda sugiere un medio húmedo y caliente ${ }^{4}$. Deducimos, por tanto, que lo normal es que el estiércol se mantenga húmedo, al menos mientras está "haciéndose». Lo cual nos lleva a pensar que, con el adjetivo siccum, Columela tal vez se refiera a un estiércol viejo, que no necesita más humedad por haberse "estabilizado». Si aceptáramos esta interpretación, resultaría que a la opción preferible en 3,11,4 de un fiemo seco y viejo seguiría — sin razón aparente_ la opuesta, la del estiércol más reciente posible, forzosamente húmedo, que sin necesidad se califica como «de otra clase». Anotemos que, poco después de mencionar el siccum fimum que nos ocupa, el mismo pasaje $(3,11,4)$ alude a un estiércol envejecido aplicándole el adjetivo uetustum, no siccum: es el estiércol añejo, cuya principal virtud consiste en que no produce hierbas.

\section{Cuándo debe estar bien Seco el estiércol}

A lo largo de la $R R$, encontramos un par de veces la recomendación expresa de que el estiércol esté seco. Por ejemplo, al tratar de la siembra de la lenteja, por la facilidad con que la humedad echa a perder esta legumbre ${ }^{5}$, o cuando necesitamos producir humo para castrar las colmenas ${ }^{6}$ : en ambas ocasiones el motivo es evidente y en ambas — detalle quizá no menor- el adjetivo usado es aridum, no siccum. En 5,9,14, en cambio, al tratar del abonado de los olivos, se recomiendan con ese objeto cantidades determinadas de estiércol de cabra (singulis stercoris caprini sex librae = para cada uno, 6 libras), de "estiércol seco" (stercoris sicci modii singuli = un modio por árbol) o de alpechín sin sal (amurgae insulsae singulis congii $V I=$ "para cada uno, 6 congios»). Como en 3,11,4, también aquí resulta raro ese genérico «estiércol seco» que choca con la precisión anterior («de ca-

4 Como corresponde al proceso de fermentación y descomposición propio de la materia orgánica. De ahí que convenga disponer dos montones de estiércol, uno para el nuevo o enterizo y otro para el que está ya «hecho» y listo para su uso. Cf. Casas de Mendoza 1868, 28-30.

5 2,10,15: Lentim a dimidiata luna usque in duodecimam solo tenui et resoluto uel pingui, set sicco maxime loco, seri conuenit; nam in flore facile luxuria et umore co- rrumpitur. Quae ut celeriter prodeat et ingrandescat, antequam seritur fimo arido permisceri debet, et cum ita quatriduo aut quinque diebus requieuerit spargi. Todas las citas del texto de Columela se harán por la edición de Rodgers 2010.

6 9,15,5: Sed ubi a posteriore parte qua nullum est uestibulum, patefactum fuerit aluare, fumum admouebimus factum galbano uel arido <bubulo > fimo. 
bra») y posterior («alpechín»). ¿Cabe imaginar corruptela para stercoris sicci? La edición upsaliense no aporta variante alguna que permita rastrearla; lo cual hace pensar que, de existir, se produjo en fecha temprana. Podemos examinar, no obstante, el locus parallelus de Paladio, quien en 11,8,27 recomienda la estercoladura de los olivos en los siguientes términos: caprini stercoris sex librae uni arbori uel cineris modii singuli sufficient. Comparada la recomendación de Paladio con el texto columeliano ${ }^{8}$ actual —satis erunt singulis stercoris caprini sex librae, stercoris sicci modii singuli- de $R R 5,9,14$, no parece descabellado imaginar una confusión del copista de la $R R$, quien habría escrito stercoris (en vez de cineris del modelo) inducido por el stercoris de poco antes; y luego siccimodii, incorporando un adjetivo necesario para denotar a stercoris. $\mathrm{O}$ tal vez sicci provenga de fimi si tenemos en cuenta que Columela acaba de aconsejar, en 5,9,3, untar los dos extremos de las estacas (taleae, pali) de olivo con una mezcla de fiemo y ceniza (mixto fimo cum cinere). Aunque todo esto no pasa de ser un intento de explicar la presumible deturpación del texto genuino, desde el punto de vista del sentido resulta más verosímil la recomendación de abonar con ceniza, conservada por Paladio, que el supuesto "estiércol seco" de la parádosis columeliana. Y es que no faltan en la $R R$ pasajes que mencionen el uso como abono de la ceniza, equiparada al estiércol: véanse $2,14,5 ; 4,32,5 ; 5,10,18 ; 11,3,28 ; 11,3,38$ y $11,3,46$. Cabe, pues, reconstruir el texto de $R R$ 5,9,14 como cineris et fimi en vez de stercoris sicci. Añadamos el testimonio de Plin. 17,53: nuper repertum oleas gaudere maxime cinere e calcariis fornacibus. Así lee el texto J. André, quien anota que Plinio se refiere a la ceniza de la leńa utilizada en los hornos de cal, a diferencia de Colum. 5,9,17, que aconseja servirse de la cal misma9 ${ }^{9}$. Presumimos, sin embargo, que Plinio está refundiendo más de un pasaje de Columela, y quizá debamos leer ...cinere e $<$ t calce e $>$ calcariis fornacibus. En cualquier caso, la alusión a la ceniza para abonar los olivos, como hallazgo reciente (nuper), apunta a nuestro Columela y a la presencia de cinis en su recomendación. Por todo ello, lo más prudente será dejar en suspenso y sin efecto la referencia a un «estiércol seco» específico en 5,9,14.

\section{Cómo FERTILIZAR El TERreno PARA REPLANTAR Viña}

Examinaremos ahora a fondo el paso de la $R R$ que suscita nuestra pesquisa y procuraremos allegar cuanto pueda arrojar luz para entenderlo y, si es posible, recuperarlo en su forma primera ${ }^{10}$. A tal efecto, empieza por llamar nuestra atención en la transmisión del texto la ausencia del adjetivo sicco en gran parte de los manuscritos. Tanto el Sangermanensis (S) como el Ambrosianus (A), los dos códices más antiguos, del siglo Ix, más algunos recentiores (h) que siguen a $\mathrm{A}$, traen un texto con el sustantivo fimo, sin más. Esta particularidad puede interpretarse como un indicio más de la temprana alteración del original. El hecho es que solo la línea de transmisión itálica presente en los mss. R (los recentiores o humanísticos), deudora de un modelo desaparecido, de filiación propia, ha preservado sicco. En la otra línea de transmisión, la de $S$ y A, la eliminación se habría producido

7 Rodgers 1975, 199. En Pallad. 3,18, 5-6 (Rodgers $1975,87)$ las referencias al abonado de los olivos son genéricas.

8 Aparentemente, falta en Paladio el tercer abono mencionado por Columela, el alpechín sin sal. Lo recomendará muy poco después, en este mismo parágrafo 11,8,2, junto con la orina añeja (amurca insulsa uel uetus urina), para abonar el olivo taladrado con la terebra Gallica.
9 André 1964, 37 y 132. Para remediar la mala calidad del terreno, Columela aconseja, en efecto, en $5,9,17$, rodear los olivos con profundos alcorques que se rellenan de cal. El texto de Plinio, según nos ha llegado, no parece muy lógico.

${ }^{10}$ Lo que sigue quedó esbozado, de forma sumaria y algo diferente, en nuestro artículo-reseña sobre la edición de Rodgers: García Armendáriz 2011, 287-288. 
en un antepasado común, favorecida por la similitud gráfica de ambas palabras. Con todo, el texto mantenía cierto sentido, al menos leído sin demasiada exigencia.

Así pues, Columela habría escrito algo antes de fimo; pero, como vimos al principio, lo transmitido por R, sicco, no resulta satisfactorio. De ahí que Rodgers, en el aparato de su edición, lo considere suspecto — sicco $R$, uix recte - y recoja la conjetura de Winterbottom — asinino dub. Winterbottom (cf. 11. 3. 12) — basada en que Columela elogia en 11,3,12 el estiércol de asno, considerándolo el más adecuado para el huerto. A 11,3,12 añadimos nosotros 2,14,4, donde se alaba el estiércol de asno como el mejor entre los del ganado (pecudum stercus) «en razón de que este animal mastica muy lentamente y digiere así con más facilidad, dando un fiemo bien triturado y listo para ir derecho al campo.» Aunque no acabe de convencernos, la interesante propuesta de Winterbottom viene a reconocer, implícitamente, la necesidad de hacer más preciso el sustantivo, demasiado genérico por sí solo o con el adjetivo siccum. Es decir, lo que el lector espera aquí es la referencia a un tipo particular de fiemo o abono, esté «seco» o no.

En este punto, convendrá recordar las clases de abono mencionadas por Columela en el decimocuarto capítulo del libro II, tras afirmar $(2,13,4)$ que a continuación va a tratar ese asunto de forma más completa que «los autores antiguos». Comienza por las tres clases principales (Tria igitur genera stercoris sunt praecipue...): ocupa el primer lugar el estiércol de ave (siendo el mejor la palomina, después el de gallinas y demás volatería, aunque debe rechazarse el de las aves acuáticas); vienen luego el humano (si se mezcla con otros desechos de la casa) y la orina envejecida, que es muy beneficiosa para vides y árboles frutales y que puede mezclarse con alpechín también añejo y libre de sal (sobre todo para los olivos, en invierno); y en tercer lugar, el estiércol del ganado, empezando por el de asno y siguiendo por el de oveja y el de cabra; luego, el de las restantes bestias de carga y ganado mayor; el de cerdo se considera el peor. Estos tres grandes grupos constituyen el estiércol producido por animales. De pasada, Columela también ha mencionado, como elementos de mezcla, otros dos tipos: uno heteróclito, el de la basura de la casería, y otro de origen vegetal, el alpechín, que procede de la molturación de las olivas. No extrańa, pues, que enseguida (2,14,5-6) continúe su enumeración con otros materiales que «son de bastante provecho» (la ceniza, el hollín) o que «aportan el vigor del mejor estiércol» (frutex lupini succisus = el tallo de altramuz, cortado). Y completa el elenco con desperdicios variados, casi siempre vegetales o de mezcla: mantillo, hojas secas recogidas en zarzales, setos o caminos; helechos; residuos del corral, cenizas, cieno, pajas, barreduras. Ya en el capítulo decimoquinto, añade, como un recurso más para acrecentar la fertilidad, lo que vio hacer a su tío Marco, seguramente en la Bética: la mezcla de tierras, para compensar con unas las deficiencias de otras $(2,15,4)$. Por último, insiste en «el sencillísimo recurso del altramuz» y da instrucciones detalladas para su cultivo y aprovechamiento como estiércol, dedicando a ello dos parágrafos nada menos (5 y 6 ).

¿Hay entre estos tipos de abono alguno en particular que cuadre con el texto transmitido en $3,11,4$ sobre la restibilis ninea? Desde luego, no hay en 2,14-15 referencia alguna a un siccum fimum; pues, aunque en 2,14,9 trata Columela de la virtud del estiércol según sea más o menos viejo (uetustum frente a recens), no alude a su mayor o menor humedad. Y ya tuvimos ocasión de valorar las escasas menciones, en la $R R$ en su conjunto, del aridum fimum o de un supuesto siccum stercus. Nada da pie, en fin, a imaginar el «fiemo seco» como una clase singular de estiércol. Por tanto, o bien nos resignamos a seguir donde estábamos o bien tentamos una vía distinta, la de suponer que el texto de 3,11,4 está alterado y que debemos buscar la respuesta o parte de ella en otros lugares de la $R R$ : donde se hable de la vińa agotada que va a replantarse y se nos diga si, en esa tesitura, conviene echar mano de un tipo concreto de abono especialmente recomendable. 
En 2,10,1, Columela abre un capítulo dedicado a los legumina refiriéndose al altramuz: entre sus cualidades está la de servir como excelente abono para «viñas exhaustas». Lo cual enlaza directamente con el asunto de 3,11,4, el de volver a plantar viña en un suelo desustanciado que hay que fertilizar. Dice el texto de 2,10,1: Lupini prima ratio est, quod et minimum operarum absumit et uilissime emitur et maxime ex îs quae seruntur iuuat agrum; nam uineis iam emaciatis et aruis optimum stercus praebet... Nuestro autor tiene comprobado que el altramuz, lo mismo que otras leguminosas, fertiliza la tierra. Así lo afirma, con especial seguridad para el lupinus, en 2,13,1, donde recoge el sentir de Saserna: Sed ex is quae rettuli seminibus idem Saserna putat aliis stercorari et iunari agros, aliis rursus peruri et emaciari: stercorari lupino faba uicia eruilia lenti cicercula piso. De lupino nihil dubito... ${ }^{11}$

Deja claro a continuación nuestro agrónomo que los tallos de esas leguminosas beneficiosas para el suelo deben enterrarse en él con el arado en cuanto se haya retirado la cosecha de grano o de forraje, para no dar lugar a que esquilmen la tierra antes de acabar secándose. En 2,14,5 vuelve a elogiar el altramuz de forma destacada: Quin etiam satis proficit <usus> cineris et fauillae; frutex uero lupini succisus optimi stercoris nim praebet. "Además, las cenizas y el hollín hacen buen papel como abono, y el tallo cortado de altramuz aporta el vigor del mejor estiércol.» ${ }^{12}$ Y enseguida $(2,15,5-6)$ insiste en la eficacia del altramuz como fertilizante y especifica cuándo ha de cortarse y enterrarse según la naturaleza del suelo:

Iam nero, ut ego reor, si deficiatur omnibus rebus agricola, lupini certe praesidium expeditissimum non deest; quod cum exili solo circa Idus Septembris sparserit et inarauerit idque tempestiue uomere uel ligone succiderit, uim optimae stercorationis exhibebit. (6) Succidi autem lupinum sabulosis locis oportet cum secundum florem, rubricosis cum tertium egerit. Illic dum tenerum est conuertitur...

«Pero, además, también se me ocurre a mí que incluso si el agricultor se viera privado de todas estas cosas, no le faltaría el sencillísimo recurso del altramuz: habiéndolo echado en terreno delgado hacia los idus de septiembre, y tras labrarlo y cortarlo a su tiempo con reja o legón, mostrará la fuerza del mejor estiércol. 6 En los terrenos arenosos conviene cortar el altramuz cuando ha florecido dos veces; en los arcillosos cuando ha florecido tres. En aquellos se entierra mientras está tierno...» ${ }^{13}$

Aparte de estas referencias al altramuz del segundo libro de la $R R$, encontramos otras en el úndecimo, donde, como es sabido, reaparecen contenidos expuestos en libros anteriores. En 11,2,44, por ejemplo, al tratar de las labores propias del mes de mayo, se prescribe enterrar las plantas del altramuz sembrado para estercolar la tierra: Item qui lupinum stercorandi agri causa seuit, nunc demum aratro subuertit. Siguiendo el calendario meteorológico y de labores de ese libro, llegamos a finales de agosto, cuando Columela aconseja, en concreto para las viñas endebles, sembrar altramuz en ellas para que, una vez entallecidas las plantas, puedan enterrarse al hacer la primera cava (en febrero, o a primeros de abril en sitios más fríos; cf. 11,2,16 y 35), proveyendo así a las viñas de un abonado estimable $(11,2,60)$ :

Hoc eodem tempore priusquam uineae puluerentur, si perexilis est uel terra uel ipsa uitis, lupini modî tres uel quattuor in singula iugera sparguntur et ita inoccantur; qui cum fruticauerunt, prima cum fossione conuersi satis bonum stercus uineis praebent.

11 «Ahora bien, de las semillas que he mencionado, el mismo Saserna cree que unas sirven como estiércol y son beneficiosas para los campos, y que otras, por el contrario, los queman y los dejan mermados. Las que los abonan son el altramuz, las habas, la veza, los yeros, la lenteja, la cicercha y los guisantes. No tengo duda alguna acerca del altramuz...».

12 García Armendáriz 2004, 220.

13 García Armendáriz 2004, 223. 
Finalmente, en 11,2,81 insiste nuestro autor en la fama de las leguminosas como abono del terreno (recuérdese la opinión de Saserna, anotada en 2,13,1), así como en la necesidad, por lo que hace al altramuz, de que se corte y se entierre en flor si queremos que aproveche a la tierra (esto es, reitera lo dicho en 2,15,5-6). Y revela su predilección por este, fundada en que puede sembrarse y también recogerse en fechas convenientes para el propietario, antes de la siembra o después de la cosecha de otros cultivos, cuando la mano de obra está disponible:

Vicia et faba stercorare agrum dicuntur. Lupinum nisi in flore uerteris, nibil agrum stercoraneris. Sed nec ulla res magis uacuis operarîs aut seritur aut conditur, nam et primis temporibus ante ullam sementem possis id obruere et nouissimis post coactos fructus tollere.

De todos estos pasajes deducimos, primero, que el cultivo del altramuz, como el de otras leguminosas, mejora la calidad del suelo; y segundo, que el tallo de altramuz cortado (frutex lupini succisus) y enterrado proporciona inmejorable abono (optimum stercus praebet) a los campos desustanciados, en particular a las viñas (uineis iam emaciatis et aruis). El notable poder fertilizante del altramuz y la facilidad con que se cultiva hacen que Columela lo juzgue especialmente recomendable, no tanto para alimentar a animales y humanos como, sobre todo, para hacer las veces de estiércol. Por tanto, sentado que en la mente de nuestro agrónomo se da la ecuación frutices lupini succisi = stercus/fimum, podemos encarar con otra perspectiva la lectura de 3,11,4 y rehacer la secuencia sicco fimo (transmitida en parte de los manuscritos humanísticos), sustituyéndola por succiso lupino, lo cual daría un sentido acorde con 2,10,1 y demás pasajes citados. En fecha muy temprana y por obra de uno o más librarii, se habría producido la abreviación y el malentendido succisolupino > siccofimo; otro copista posterior, el del modelo de $\mathrm{S}$ y A, habría eliminado sicco, asimilado gráficamente con fimo y leído como duplicación. En síntesis: creemos que en 3,11,4 Columela recomendó abonar el terreno destinado a reponer una vińa con tallos de altramuz cortados, en vez de con un «fiemo seco» de dudoso sentido.

\section{Reconstrucción Del teXto}

Sustituimos, pues, sicco fimo por succiso lupino: ...prius, quidquid est residuae uitis extirpari debet, deinde totum solum succiso lupino aut, si id non sit, alterius generis quam recentissimo stercorari atque... $=$ "... (si la necesidad nos obliga a replantar una viña,) antes de hacerlo hay que quitar cualquier resto de raíces de las vides viejas y, a continuación, hay que estercolar todo el terreno con altramuz cortado o, si no se dispone de este, con el ¿...? más fresco posible de otro tipo y..." Echamos en falta un sustantivo al que referir quam recentissimo, y nos parece que lo más sencillo sería suplir fimo inmediatamente después; su gran parecido con el final del superlativo explicaría con facilidad el salto en la escritura. Es lo que propusimos en 2011, 288, juzgando razonablemente resuelta de ese modo la reconstrucción del locus, que había de leerse como sigue:

Vltima est, ut dixi, conditio restibilis uineae; nam si necessitas facere cogit, prius, quidquid est residuae uitis extirpari debet, deinde totum solum succiso lupino aut, si id non sit, alterius generis quam recentissimo <fimo> stercorari atque ita conuerti et diligentissime refossae omnes radices in summum regeri atque comburi, tum rursus uel stercore uetusto, quia non gignit herbas, uel de uepribus egesta humo pastinatum large contegi. 
El sentido del pasaje queda así restablecido. Coherente con sus propias prescripciones de otros lugares del tratado, Columela recomienda en 3,11,4 tallos de altramuz cortados y enterrados como primer recurso para recuperar la fertilidad de la viña. En ausencia de esa leguminosa, propone abonar con otro tipo de fiemo «lo más reciente posible», lo cual no es de extrañar si nos atenemos al principio expuesto en 2,14,8: «Hay algo que quiero también advertir, y es que todo estiércol que ha sido depositado en su momento y ha descansado un año es el de mayor utilidad para los sembrados, pues todavía guarda entera su fuerza y no cría yerbas; en cambio, cuanto más viejo sea, aprovecha menos, porque tiene menos vigor. De manera que debe echarse en los prados el más nuevo (quam recentissimum), por ser el que puede producir más abundancia de yerbas...» ${ }^{14}$ En 3,11,4 la razón de estercolar con fiemo muy reciente (si no se tiene altramuz en verde) es que aporta más vigor: «...primero tenemos que extirpar cualquier resto de cepas, luego estercolar todo el terreno con altramuz cortado o bien, en caso de no disponer de él, con fiemo de otra clase, lo más reciente posible, y entonces revolverlo ${ }^{15}$, y volver a sacar a la superficie cuantas raíces hayamos removido sin dejar una, y quemarlas; a continuación, hay que volver a cubrir generosamente el terreno desfondado, sea con estiércol añejo (porque no cría hierbas) sea con mantillo traído de los zarzales.» Esto es, el estiércol más reciente (capaz de producir muchas hierbas indeseables si estuviera arriba) se ha mezclado en profundidad con tierra y ceniza, enriqueciendo el suelo considerablemente; en cambio, el abono usado en lo más somero no criará hierba.

\section{VARIANTES DE LECTURA}

Creemos haber recuperado en los párrafos anteriores el verdadero sentido de lo escrito por Columela, mas no por ello estamos seguros de haberlo recuperado en su literalidad. Pueden subsistir alteraciones que afecten solo a la forma. El verbo stercorare, por ejemplo, no suele ir acompańado, en la $R R$, de especificación instrumental ${ }^{16}$. Desde luego, no es imposible que aquí la lleve, pero es que, por otro lado, la frase final — tum rursus uel stercore uetusto... uel... pastinatum large contegi-, que expresa que "hay que volver a cubrir...", sugiere la presencia, precisamente en el punto que nos ocupa, de un verbo de semántica afín a este último.

Por su similitud formal con sterc-, el primero que se nos ocurre sería sterno, leyendo de este modo: ... debet,...totum solum succiso lupino aut, si id non sit, alterius generis quam recentissimo stercore <sterni> atque ita conuerti... En paralelo con uel stercore vetusto...contegi del final, se empieza por cubrir todo el suelo con el estiércol más fresco disponible. Paleográficamente, pasar de stercoresterni a stercorari resulta factible. Ahora bien, existe el inconveniente de que, en la $R R$, sterno apenas se encuentra como verbo simple ${ }^{17} \mathrm{y}$, entre sus compuestos, solo consterno podría convenirnos por su significado ${ }^{18}$. Es habitual, en efecto, que consterno se construya con ablativo $^{19}$ y exprese la acción de «solar», esto es, "cubrir el suelo con un material determina-

14 García Armendáriz 2004, 221-222.

15 Se supone que con el arado, dando una reja al terreno, o quizá a mano, con el legón.

16 En la obra de Columela encontramos solo un ejemplo de stercorare acompańado de ablativo instrumental ("estercolar o abonar con...»), en 11,3,28: plantam... multo cinere stercorabimus. En los otros veintiocho casos de uso de este verbo, simplemente se nombra lo que está abonado o se quiere abonar, sin especificar con qué.
17 Aparece en dos ocasiones $(4,2,2$ y $5,4,2)$ sin ablativo, referido a cepas "(ex)tendidas» sobre el suelo ; y una sola vez con ablativo y en la acepción de "solar», "pavimentar» $(6,23,1$ : stabula sunt optima saxo aut glarea strata), si bien para esta última acepción el verbo habitual es, sin duda, con-sterno.

18 No tomamos en cuenta substerno, supersterno y prosterno, cuyos significados no serían acordes con lo expresado en nuestro pasaje. 
do $»^{20}$. En general, más allá de la $R R$, las acepciones de sterno y consterno (en parte, también substerno), tienden a concentrarse en dos significados, los de "(ex)tender, disponer una alfombra o jergón», o bien "pavimentar, preparar una superficie para su uso»; en ambos casos se trata de cubrir el suelo, aunque con materiales de diverso tipo y con distinto fin. De ahí que podamos encontrar la construcción con o sin ablativo instrumental, según quiera señalarse el material con que se cubre el suelo o simplemente la acción de (ex)tender algo ${ }^{21}$.

Pero no es -sterno el único verbo que cabe considerar aquí. Otro verbo cuya semántica encajaría es spargo, o alguno de sus compuestos. Puesto que la sintaxis pide "cubrir con (+ ablativo)», y no «esparcir (+ acusativo)», Columela pudo haber usado un compuesto como conspargo, con régimen en ablativo y muy presente en la $R R$ (trece ejemplos). Si nos centramos en el simple, spargo suele aplicarse a la acción de «sembrar» (equivaliendo a sero o semino) y, tanto él como sus compuestos, se refieren con cierta frecuencia a líquidos (significando «rociar», "asperjar») 22 , de manera que en ambos usos es posible apreciar la noción común de «arrojar sobre una superficie partículas menudas, sólidas (semillas, partículas de cualquier material) o líquidas (gotas)». De ahí que spargere valga por «esparcir, diseminar cualquier cosa, incluido estiércol» ${ }^{23}$, pudiendo también expresar -y esto es ahora lo relevante- la idea de "rociar o cubrir con (cualquier cosa, incluido estiércol)». Refiriéndose a la siembra de nabos y nabas, dice Columela $(2,10,4)$ : Ingerum agri non amplius quattuor sextariis raporum seminis obserendum est; quarta parte amplius napi spargendum, quia non in uentrem latescit sed tenuem radicem deorsum agit. Es decir: «[una yugada de tierra] ha de sembrarse con una cuarta parte más [de simiente de nabos que de nabas] ${ }^{24}$. El uso de spargo con ablativo se encuentra ya en Virgilio —en ...sparge fimo pingui [sc. solum, agrum]...— de georg. 2,34725, donde spargo equivale a -sterno o -tego, con su complemento en ablativo, y donde incluso la referencia al abonado (fimo pingui) favorece nuestro intento de recuperar la letra de 3,11,4, que finalmente quedaría de este modo:

...debet,...totum solum succiso lupino aut, si id non sit, alterius generis quam recentissimo stercore $<$ spargi $>$ atque ita conuerti... $=$ «... hay que...cubrir todo el suelo con altramuz cortado o, si no se dispone de este, con estiércol de otra clase, lo más fresco posible, y luego revolverlo..."

19 En 1,6,12, donde consterno significa "pavimentar», el instrumental está implícito en el contexto, al describirse la acción en detalle; parecidamente en $8,5,11$. Solamente en 3,13,2 lo encontramos sin ablativo y en la acepción de «tender» (única aparición de consterno en la viticultura de la $R R)$.

20 Como, por ejemplo, en 12,52,4: Horum lacusculorum solum lapide uel tegulis oportet consterni et ita decliue fieri... Tanto en ese lugar como en 1,6,23; 6,30,2; 7,4,5 y 7,6,6, el texto se refiere a preparar el suelo usando material de albañilería (piedra, ladrillo...) o bien madera; en $8,15,3$ y 9,1,2 se precisa que debe utilizarse el opus Signinum. En 7,3,8 y 8,5,3, en cambio, lo que debe cubrir el suelo es paja o algo equivalente (un material más cercano al estiércol de nuestro pasaje). En 10,16 —iniussi consternitur ubere mali- el significado es hiperbólico, en contexto poético.

21 Ver OLD, s. v. (con-, sub-) -sterno.

22 Véase, por ejemplo, $R R$ 10,301-302: ...croceosque corymbos / sparge mero Bacchi...

23 Véase 2,9,9 (ibi columbinum stercus uel, si id non est, folia cupressi conuenit spargi et inarari); 2,15,2 (puluerem stercoris per segetem spargere);11,2,18 (pars [stercoris] oleis et ceteris arboribus inspargenda); 11,2,85; 11,2,86 (modios quinos stercoris spargere); 11,2,87.

24 El ejemplo aducido muestra la equivalencia de spargo y (ob)sero, usados en léxica variatio, así como la variación sintáctica en el uso de amplius.

25 Otro ejemplo de spargo con ablativo en las Geórgicas: ...prius haustu sparsus [sc. tu] aquarum... (4,229). 


\section{Posibles objeciones}

Primera. Cuando, en el libro II, trata Columela de los recursos para fertilizar los campos, se refiere a que su tío Marco, a quien tanto admiraba, ...negabat stercus uitibus ingerendum, quod saporem uini corrumperet $(2,15,5)^{26}$. Alguien podrá extrañar que en $3,11,4$ su sobrino recomiende el estiércol más fresco (precisamente el más fuerte) para restablecer la fecundidad del suelo de la restibilis uinea. Mas es evidente que nuestro escritor no sentía el escrúpulo de su tío. Son muchos los lugares de la $R R$ donde se aconseja estercolar las vides: sea sin precisar el tipo de estiércol $(3,9,9$; $3,11,9 ; 3,15,5 ; 5,6,21)$; sea con fiemo de aves en general o con palomina, el más preciado $(8,1,2$; 11,2,87); sea (en 4,8,3) ofreciendo una triple elección, la de fimum —estiércol fresco de ganado mayor, seguramente-, palomina u orina añeja $\mathrm{a}^{27}$. Nótese, además, que en 3,11,4 el fimum o stercus quam recentisssimum se da como segunda opción — solo si no se dispone de altramuz- y que ese estiércol irá a una capa inferior del suelo, no a la superficie, de una viña nueva que aún debe plantarse y que tardará en dar fruto.

Segunda. Nos detendremos ahora en el pronombre id, que recoge la alusión al supuesto sicco fimo del textus receptus o, según nuestra conjetura, a succiso lupino. Claro está que esperamos aquí la concordancia en género gramatical, y la cuestión no es sencilla si tenemos en cuenta que tanto fimu-como lupinu- se documentan con género neutro o masculino. Para el género del primer sustantivo, remito a $O L D$, s.v. fimum, y añado que las cinco ocurrencias de fimum en la $R R$ están en acusativo: es decir, no tenemos la absoluta certeza de que sea neutro ${ }^{28}$. En cuanto al segundo, en la $R R$ se encuentra lupinum (neutro), en 2,7,1 y 2,15,5, y lupinus (masc.) en 6,25,1; el resto de ocurrencias puede adscribirse, por su forma, a cualquiera de los dos ${ }^{29}$. Sin embargo, la doble posibilidad del nominativo respondería a una distinción semántica. En 2,7,1 y 2,15,5 la referencia al altramuz es genérica, como planta - lo mismo que en succiso lupino de 3,11,4; de hecho, en 2,15,5 también se habla de cortar sus tallos ${ }^{30}$-, mientras que en 6,25,1 Columela se refiere a los frutos, los altramuces (lupini semicrudi conteruntur) ${ }^{31}$. Por tanto, nuestra hipótesis no encuentra aquí inconveniente.

Tercera. Puesto que - de acuerdo con nuestra lectura- Columela prescribe en 3,11,4 que, faltando altramuz en verde, hay que «estercolar con fiemo / cubrir con estiércol de otra clase, lo más fresco posible, todo el suelo", entendemos que el lupinum se considera una clase de fimum o stercus. ¿Es así realmente? Sin entrar en detalles que exigirían demasiado espacio, sí diremos que a) stercus es la voz más genérica y, como tal, de uso preponderante en la $R R$ (así como en otros autores), muy por encima de fimum $^{32}$; b) no es difícil aportar ejemplos en los que stercus significa genéricamente

26 Paladio retomará en 9,2 el consejo de no abonar las viñas con estiércol, sin mencionar su paternidad y refundiéndolo con otros de Columela.

27 En el caso de esta, Columela afirma $(2,14,2)$ que no solo aumenta la producción de vińas y frutales, sino que incluso mejora el sabor y el aroma del vino y de la fruta.

28 La misma ambigüedad es recogida en TLL VI, 765-766, s.v. fimum: ...formam -us masculinam, semper singularem praescribunt grammatici (..) forma -um neutrius generis solemnis est ante Christianorum tempora. Forma -us masc. generis legitur.

29 Véase Betts-Ashworth 1971, 212 (fimum) y 316317 (lupinum).
30 Es asimismo el caso de 11,2,60: ...qui [sc. lupini] cum fruticauerunt, prima cum fossione conuersi [sc. frutices] satis bonum stercus uineis praebent.

31 La misma diferenciación, en líneas generales, muestran los ejemplos de OLD (s.v. lupinum): neutro para la planta, masculino para los frutos. En cambio, una obra tan importante como André 1985, 148 es en este caso claramente insuficiente.

32 Cf. Betts-Ashworth 1971, 212 (fimum) y 553554 (stercilin(i)um, stercoratio, stercoratus, stercoro, stercorosus, stercus). Ver también TLL VI, 766, s.v. fimum: de usu (comparado con stercus). 
«abono», más que «estiércol» (asociado este al excremento animal), por lo que puede incluir desechos diversos tales como orina ${ }^{33}$, ceniza $^{34}$, alpechín, hojarasca, mantillo de setos y zarzales...o altramuz en verde ${ }^{35}$; c) el caso de fimum es algo distinto, pues puede servir como mera variatio o doblete léxico de stercus, en acepción muy general ${ }^{36}$, pero asimismo se encuentra con un significado preciso de "heces de ganado mayor», a menudo en fresco ${ }^{37}$. Así las cosas, nuestra propuesta de leer alterius generis quam recentissimo stercore <spargi> parece preferible a alterius generis quam recentissimo $<$ fimo $>$ stercorari.

\section{El altramuz en Verde como abono}

El uso de tallos de altramuz, cortados y enterrados para enriquecer el suelo, representa un caso particular del abonado en verde, técnica practicada desde la Antigüedad hasta hoy mismo y en muy diversos países. Puede verse al respecto la monografía de Pieters 1927, con una breve historia de dicha práctica agrícola en su segundo capítulo; para una perspectiva más amplia, puede consultarse la obra de Mazoyer-Roudart 2002 [1997], donde no falta la mención de l'engrais vert (421-422) como medio de fertilización. Si nos ceñimos al abonado en la agricultura antigua, en particular la romana, contamos con el artículo de González Marrero \& Ríos Longares 2014, quienes no dejan de referirse a los abonos en verde y al papel destacado del altramuz (189) ${ }^{38}$. Más amplio en su objeto, y menos sistemático, resulta el libro editado por R. Jones, Manure Matters: Historical, Archaeological and Ethnographic Perspectives (Jones 2012). Contiene, desde luego, alusiones dispersas al abonado en verde, y en concreto al realizado mediante el altramuz, como práctica habitual desde la Edad Antigua ${ }^{39}$; lo que no encontramos en él es una síntesis ordenada de contenidos referentes

33 Cf. 11,2,87: ...eodem tempore uineis ablaqueatis columbinum stercus ad singulas uites, quod sit instar unius sextarii, uel urinae hominis congios uel alterius generis quaternos sextarios stercoris infundere.

34 En 4,32,5 se nos dice que el cañaveral ha de abonarse cinere uel alio stercore; y en 11,3,28, tratando del cultivo del cardo, que ...multo cinere stercorabimus. Id enim genus stercoris huic holeri uidetur aptissimum. Lo que leemos en 11,3,46, al tratar del espárrago (mox uel stercus uel cinis iniciendus), creemos que puede entenderse del mismo modo (= la ceniza es un tipo de abono), aunque a primera vista parezca decir lo contrario.

35 Véanse los loci reseñados en el apartado 3, que confirman el destacado papel como abono que Columela asigna al altramuz. En 2,10,1; 2,14,5; 2,15,5; $11,2,44$ y 11,2,60 aparece stercus, o un derivado de stercus, en relación gramatical directa y expresa con lupinum. Queda claro que, para nuestro autor, el altramuz en verde es ante todo un abono.

36 Así en $1,6,22 ; 2,5,1 ; 2,17,2 ; 7,5,8 ; 10,81$. Un ejemplo claro, a nuestro juicio, de variatio en $6,30,8$ y 10 .

37 Es significativo que, en los párrafos dedicados a los tipos de abono en el libro II (2,14-15), nuestro au- tor usa siempre stercus, con la determinación correspondiente en cada caso; solo una vez, refiriéndose a las heces del asno, usa, solo, el sustantivo fimum $(2,14,4)$. El mismo significado de heces frescas de ganado mayor, en $4,6,8 ; 5,9,3 ; 6,6,4 ; 6,30,10 ; 10,82 ; 11,3,23$ y 25 . Un apartado especial lo constituyen los usos del fimum (el de buey - bubulum - en concreto) en la apicultura; suponemos que se usaba en fresco (aluei ex fimo ficti: 9,6,2) o seco (bubulo fimo incenso: 9,14,1; et alibi).

38 El programa del Coloquio «Columelle et les céréales», recién celebrado en Lyon (25 y 26 sept., 2018), incluye la comunicación de J. Trinquier titulada «La fumure dans le livre II de Columelle». Ya vimos que el libro II de la $R R$ contiene la exposición más sistematizada, en las fuentes antiguas, acerca de los abonos.

39 Jones recoge algunas indicaciones sobre el tema. Primero la genérica de Catón acerca del estiércol vegetal, y luego la explícita preferencia de Varrón por los altramuces (Jones 2012, 7) Por su parte, R. Shiel concede no poca atención a la agronomía antigua (en particular, a Columela) y termina su estudio con una alusión al destacado papel del altramuz en la $R R$ (Shiel 2012, 23). Otro capítulo del mismo libro que tiene muy presentes las obras antiguas de agronomía es el de D. Varisco, titulado "Zibl and Zirä'a: Coming to Terms with Manure 
a las variedades de estiércol o abono en las fuentes clásicas. En consecuencia, hemos rastreado por nuestra cuenta las menciones del altramuz anteriores a Columela, a la búsqueda de precedentes en su uso como abono. Pretendemos calibrar hasta qué punto la firme recomendación que de él se hace en la $R R$ reitera usos tradicionales, ya descritos, o bien presenta alguna originalidad.

En las fuentes griegas, el altramuz $\left(\theta \varepsilon \dot{\varepsilon} \rho \mu_{\varsigma}\right)$ es nombrado como legumbre comestible, juzgada alimento vil de gente pobre (Alexis, Ateneo, Dífilo, Diógenes Laercio, Licofrón), o por su valor medicinal (Hipócrates, Dioscórides) ${ }^{40}$. Teofrasto, en Historia de las Plantas ${ }^{41}$, insiste en su naturaleza casi silvestre $(1,3,6 ; 3,2,1 ; 8,7,3 ; 8,11,2$ y 8$)$ y aconseja la siembra superficial y temprana $(1,7,3$; $8,1,3 ; 8,11,8)$; compara el fruto con el de ciertos arbustos que crecen junto al mar $(4,7,5$ y 7$)$ o bien observa cómo germina $(8,2,2)$, o constata su larga duración para simiente $(8,11,6)$. Sin embargo, no hemos localizado en esta obra, como tampoco en Sobre las causas de los vegetales, alusión al uso de la planta como abono en verde. Todo indica que el cultivo del altramuz tenía una importancia menor en la agricultura griega; como apunta S. Amigues en nota a hist. $8,11,8^{42}$, es probable que esta escasa importancia, unida a su consideración de especie semisalvaje, tenga que ver con la exigencia de suelos no calizos, por lo que cultivarlo resultaba dificultoso en gran parte de Grecia.

El caso es distinto si nos situamos en época y ambiente romanos. Los testimonios de la utilización y el aprecio de la planta del altramuz como abono comienzan con Catón, quien lo cita $(37,2)$ en primer lugar — seguido por habas y veza- como cultivo que por sí mismo fertiliza el terreno, y lo incluye luego (se entiende que en referencia a sus tallos, a la planta, verde o seca) como materia de abono, junto a otras especies vegetales ${ }^{43}$. Varrón es más preciso, constituyendo un claro antecedente de lo que leemos sobre el tema en la $R R$. El párrafo trascrito a continuación $(1,23,3)$ es explícito sobre el abonado con leguminosas, en particular altramuces y habas ${ }^{44}$ :

Quaedam etiam serenda non tam propter praesentem fructum quam in annum prospicientem, quod ibi subsecta atque relicta terram faciunt meliorem. Itaque lupinum, cum minus siliculam cepit, et non numquam fabulia, si ad siliquas non ita peruenit ut fabam legere expediat, si ager macrior est, pro stercore inarare solent.

La diferencia respecto a lo visto en Columela consiste en que, mientras dicha práctica es para Varrón la manera de sacar provecho a unas plantas de altramuz o de habas que no llegan a granar satisfactoriamente, Columela aprecia en sí misma la cualidad del altramuz de abonar la tierra desustanciada; es decir, el Gaditano subraya el poder fertilizante de la planta y le da mayor relevancia dentro de su doctrina agrícola. En cambio, nada encontramos sobre dicha virtud del altramuz en Virgilio, quien lo menciona una sola vez, en georg. 1,75-7645. El altramuz cultivado de los

in Arab Agriculture» (Varisco 2012). Debemos advertir que, en general, la forma de citar de Jones es manifiestamente mejorable. Las referencias a textos clásicos se hacen, cuando se hacen, por la página correspondiente de la traducción inglesa consultada, que suele ser la de The Loeb Classical Library: el lector debe acudir a ella para ver de qué lugar del texto original se trata.

40 El detalle de estos testimonios en García Soler 2001, 70 y Dalby 2003, 201.

41 Para las obras de Teofrasto (Historia de las plantas y Sobre las causas de los vegetales) nos servimos de la edición de S. Amigues: Amigues 2003-2006 y Amigues 2012-2017.

\footnotetext{
42 Amigues 2003-2006, IV 236.

43 Goujard 2002, 41. Catón menciona el altramuz en otras cinco ocasiones.

44 Heurgon 2003, 52. Hay cuatro menciones más del altramuz en la obra de Varrón.

45 Donde describe con expresividad característica los rasgos de la planta — de tallos endebles (fragilis calamos) y masa vegetal sonora (siluamque sonantem) por el ruido causado al ser agitadas las vainas-, a la cual asigna en hipálage un epíteto (tristis) que aludiría al sabor amargo, desagradable, del fruto. Ver Mynors 1990, 17; Maggiulli 1995, 350 .
} 
auctores rei rusticae es con seguridad Lupinus albus L., bien diferenciado ya (frente a lo que parece suceder en la Grecia de Teofrasto) de su propio ancestro silvestre ${ }^{46}$. La distribución geográfica de las variedades silvestres de Lupinus albus L. sugiere que esta leguminosa habría sido domesticada en algún lugar de la cuenca del mar Egeo, si bien los restos arqueológicos anteriores a época romana son muy escasos; de hecho, su total ausencia en yacimientos neolíticos mediterráneos apunta a que la domesticación fue relativamente tardía ${ }^{47}$.

Después de Columela, y sirviéndose de él como fuente destacada, Plinio trata de los diversos tipos de estiércol $(17,50-57)$ sin dejar de anotar la opinión general sobre la virtud del altramuz como abono en verde (17,54): Inter omnes autem constat nibil esse utilius lupini segete, priusquam siliquetur, aratro uel bidentibus uersa manipulisue desecta circa radices arborum ac uitium obrutis ${ }^{48}$. Luego, en 18,133-136, dedica considerable atención al cultivo del altramuz, recordando que fertiliza la tierra: Pinguescere hoc satu arua uineasque diximus $(18,134)^{49}$. Unos siglos más tarde, Paladio, deudor también de Columela, insistirá $(9,2)$ en la utilización del altramuz como abono para viñas pobres:

Hoc tempore [sc. mense Augusto], si terra exilis in uinea est et uinea ipsa miserior, tres uel quattuor lupini modios in ingeros spargis [fort. sparges] atque ita occabis. Quod ubi fruticarit euertitur et optimum stercus praebet in uineis, quia laetamen propter uini uitium non conuenit inferre uinetis. ${ }^{50}$

La continuidad del abonado en verde y la preeminencia del altramuz para este cometido están bien atestiguadas en la historia agraria occidental ${ }^{51}$. En Italia, por ejemplo, dicha práctica era común a principios del siglo XIX, si nos atenemos a las noticias de Filippo Re en su obra sobre los abonos: véase el capítulo xix, donde trata del enterramiento de altramuces o de habas en flor, en la Toscana y otros lugares ${ }^{52}$. En cuanto a Francia, la Maison rustique du XIXe siècle, obra dirigida por M.C. Bailly, dedica varias páginas al abonado «a partir de las plantas terrestres», en verde ${ }^{53}$. Cita testimonios de autores griegos y romanos, en particular los de Varrón y Columela, con altramuces y habas como especies predilectas; da como habitual en su tiempo esa práctica en Italia y menciona asimismo distintas partes de Francia. Asegura que este tipo de abono es más propio de las tierras meridionales, por ser más provechoso para los suelos secos que para los húmedos, y enuncia un principio de compensación en la mejora de terrenos que era ya conocido - afirma- de los romanos. Termina anotando que el momento de la floración es el más adecuado para enterrar la planta, pues es entonces cuando se encuentra llena de sustancias nutritivas y no ha comenzado to-

46 Esta y otras especies silvestres (por ejemplo, Lupinus angustifolius $\mathrm{L}$.) aparecen denotadas en los textos latinos con adjetivos como agrestis, silvestris o montanus: André 1985, 148; Abbe 1965, 121.

47 Es lo que concluyen Zohary, Hopf \& Weiss 2012, 99.

48 André 1964, 38. Aunque André lee desectae, parece preferible desecta, como antes uersa, referidos ambos participios, en femenino singular, al cultivo, es decir, a las plantas de altramuz (seges lupini), «volteadas con arado o bidentes, o bien cortadas en haces que se entierran en torno a las raíces de árboles y vides.»

49 Le Bonniec \& Le Bøuffle 1972, 102. En 22, 154157, expondrá la virtud medicinal de los altramuces, que pueden ser silvestres o cultivados (André 1970, 76-77).
50 Rodgers 1975, 177. Paladio resume aquí varios consejos de Columela, incluido uno que en realidad es de Marco Columela, tío de nuestro autor: el de no abonar las viñas con estiércol.

51 En el ámbito oriental, las Geopónicas no mencionan el abonado en verde al tratar de los tipos de estiércol y de su preparación (capítulos 21 y 22 del libro II: Meana, Cubero \& Sáez 1998, 143-145). Sin embargo, el valor fertilizante del altramuz está presente —en términos muy parecidos a los que hemos observado en la agronomía romana- en otros lugares de la obra: 2,39,6; 3,5,7; 3,10,8 (Meana, Cubero \& Sáez 1998, $151-152,182,184)$.

$52 \operatorname{Re} 1815,67$.

53 Bailly 1838, 87-89. 
davía a «agotar» el suelo. En España, por último, el Diccionario de agricultura, zootecnia y veterinaria, dirigido por A. Matons y M. Rosell y Vilà, no deja de referirse a los «abonos verdes» "54. Señala que son casi exclusivamente leguminosas las plantas enterradas para tal fin, al sumar la ventaja de que su cultivo enriquece previamente el suelo con nitrógeno, y añade que suele enterrarse el último corte de las leguminosas forrajeras, antes de labrar el terreno. Precisa que la leguminosa ha de enterrarse "cuando se halla en plena floración, pues entonces ha adquirido su máximo desarrollo y, no habiendo perdido humedad, es tierna y se descompone rápidamente en el suelo» (20). Considera, en fin, el abonado en verde muy conveniente por su baratura y beneficio, aunque no como procedimiento básico para fertilizar el suelo, sino de manera complementaria. Estos tres ejemplos de bibliografía sobre el tema podrían ampliarse con otras obras ${ }^{55}$, confirmando así la existencia de una tradición perdurable y muy difundida, lo cual vendría a asentar el fundamento científico del abonado en verde, certeramente intuido desde la Antigüedad.

\section{Recapitulación}

Hemos comenzado fijando nuestra atención, dentro de $R R 3,11,4$, en la dificultad de establecer qué sea el siccum fimum transmitido por una parte de los manuscritos y adoptado hoy como lectio vulgata. La falta de sentido claro en este punto nos lleva a indagar en qué circunstancias reclama expresamente nuestro autor estiércol seco: en dos ocasiones prescribe Columela usar aridum (no siccum) fimum, para la siembra de la lenteja $(2,10,15)$ y para el fuego de castrar colmenas $(9,15,5)$. En ambas, el buen sentido avala su exigencia. En cambio, dejamos en suspenso los stercoris sicci modii singuli supuestamente requeridos por Columela para abonar los olivos en 5,9,14; tras comparar el texto con sendos loci de Paladio y Plinio, sospechamos alguna corruptela y sugerimos sustituir stercoris sicci por cineris et fimi (ceniza mezclada con fiemo).

El apartado 3 («Cómo fertilizar el terreno para replantar viña») examina primero en detalle la tradición manuscrita de 3,11,4 y valora la enmienda de Winterbottom (asinino fimo). Enseguida, a fin de sanar el texto, se impone la búsqueda de otros pasajes que puedan iluminarlo. Nuestro punto de partida son los importantes párrafos $(2,14-15)$ donde por vez primera se expone de forma sistemática el saber antiguo acerca de las clases de abono y su jerarquía: no hallamos en ellos noticia de un siccum fimum específico, mientras que es palmario el gran interés de Columela por el lupinum. Revisamos luego los lugares de la $R R$ estrechamente relacionados, por su contenido, con el que nos ocupa - a saber, 2,10,1; 2,13,1; 2,14,5; 2,15,5-6; 11,2,44; 11,2,60; 11,2,81-. Cotejados y valorados, resulta innegable la expresa e insistente recomendación, por parte de nuestro agrónomo, del altramuz en verde como abono, especialmente indicado en el caso de viñas pobres o empobrecidas. En esa evidenciada predilección de Columela se basa nuestra propuesta de leer succiso lupino en lugar de sicco fimo; de paso, señalamos la idoneidad (en cuanto a género gramatical) del sustantivo que postulamos.

Al modificar el texto y eliminar la voz genérica fimo, se hace necesario suplir un sustantivo al que referir quam recentissimo. En el apartado 4 proponemos la opción más sencilla desde el punto de vista paleográfico, que consiste en añadir fimo: ... debet ...totum solum succiso lupino aut, si id non sit, alterius generis quam recentissimo <fimo> stercorari... Con esto quedaría reconstruido el

54 Matons \& Rosell 1928, I 20-21.

55 Véase, por ejemplo, Pieters 1927, passim, con frecuentes referencias al altramuz en sus diferentes especies. 
texto en lo esencial. No obstante, tomando en consideración los usos léxicos y sintácticos propios de Columela (y eventualmente de otros autores), así como la posibilidad de variantes en la escritura (es conocida la notable alteración del original, desde fecha muy temprana), en el apartado 5 nos ocupamos de plantear algunas hipótesis que no afectan al sentido del texto. Examinadas varias opciones, encontramos razones de peso para defender la lectura quam recentissimo stercore <spargi $>$, sin descartar del todo nuestra primera hipótesis, quam recentissimo <fimo > stercorari.

Por último, el apartado 7 expone diversos datos y argumentos «externos» que confirman la conveniencia del abonado en verde con plantas de altramuz, documentando esa práctica agrícola desde la Antigüedad hasta hoy mismo. Se dedica en él especial atención a lo referente a Grecia y Roma antiguas, pero también se hace mención de países y tiempos más recientes. Parecía conveniente allegar esa información, aun de forma somera, para sustentar nuestra propuesta de leer succiso lupino en lugar de sicco fimo, mostrando cómo la ciencia agronómica va de la mano con nuestro autor en su predilección por tan humilde leguminosa.

\section{BibLIOGRAFíA}

Aвbe, E., 1965, The Plants of Virgil's Georgics, Ithaca NY: Cornell University Press.

Amigues, S., 2003-2006, Théophraste, Recherches sur les plantes, tome I (livres I et II), t. II (I. III et IV), t. III (l. V et VI), t. IV (l. VII et VIII), t. V (1. IX). Texte établi et traduit par S. Amigues, Paris: Les Belles Lettres.

Amigues, S., 2012-2017, Théophraste, Les causes des phénomènes végétaux, tome I (livres I et II), t. II (l. III et IV), t. III (l. V et VI). Texte établi et traduit par S. Amigues, Paris: Les Belles Lettres.

André, J., 1964, Pline l'Ancien, Histoire Naturelle, livre XVII. Texte établi, traduit et commenté par J. André, Paris: Les Belles Lettres.

André, J., 1970, Pline l'Ancien, Histoire Naturelle, livre XXII. Texte établi, traduit et commenté par J. André, Paris: Les Belles Lettres.

ANDRÉ, J., 1985, Les noms de plantes dans la Rome antique, Paris: Les Belles Lettres.

Bailly, M. C., 1838, Maison rustique du XIXe siècle. Encyclopédie d'Agriculture pratique, cuvre dir. par M. C. Bailly, t. I, Paris: Librairie Agricole de la Maison Rustique.

Betтs, G. G., \& W. D. Ashworth, 1971, Index to the Uppsala edition of Columella, Uppsala: Almquist \& Wiksell.

Casas de Mendoza, N., 1868², Tratado de agricultura española teórico-práctica, Madrid: Calleja y Cía.

Dalby, A., 2003, Food in the Ancient World from A to Z, London-New York: Psychology Press.

García Armendáriz, J.-I., 2004, Columela, Libro de los árboles. La labranza, libros I-V; introducción, traducción y notas de Autor, Madrid: Gredos.

García Armendáriz, J.-I., 2011, artículo-reseńa sobre Rodgers 2010, ExClass 15, 273-298.

García Soler, M. J., 2001, El arte de comer en la antigua Grecia, Madrid: Biblioteca Nueva.

González Marrero, J. A., \& R. Ríos Longares, 2014, «Técnicas para fertilizar el suelo en Roma: los tratados de agri cultura», Fortunatae 25, 183-197.

Goujard, R., 2002, Caton, De l'agriculture. Texte établi, traduit et commenté par R. Goujard, Paris: Les Belles Lettres.

Guiraud, Ch., 2003, Varron, Économie rurale, Tomes II et III (livres II et III). Texte établi, traduit et commenté par Ch. Guiraud, Paris: Les Belles Lettres.

Hedberg, S., 1968, L. Iuni Moderati Columellae Rei Rusticae libri III-V, rec. S. Hedberg, Upsaliae : Almquist \& Wiksell.

Heurgon, J., 2003, Varron, Économie rurale. Tome I (livre I). Texte établi, traduit et commenté par J. Heurgon, Paris: Les Belles Lettres. 
Jones, R., 2012, "Why Manure Matters», en R. Jones ed., Manure Matters: Historical, Archaeological and Ethnographic Perspectives, Farnham-Burlington VT: Ashgate, 1-11.

Le Bonniec, H., \& A. Le Boeuffle, 1972, Pline l'Ancien, Histoire Naturelle, livre XVIII. Texte établi, traduit et commenté par H. Le Bonniec avec la collaboration de A. Le Bœuffle, Paris: Les Belles Lettres.

LuCARini, C. M., 2014, «Ad Columellam», Mnemosyne 67, 648-659.

Maggiulli, G., 1995, Incipiant silvae cum primum surgere. Mondo vegetale e nomenclatura della flora di Virgilio, Roma: Gruppo Editoriale Internazionale.

Matons, A., \& M. Rosell, 1928, Diccionario de agricultura, zootecnia y veterinaria, dirigido por A. Matons y M. Rosell y Vilà, tomo I, Barcelona: Salvat.

Mazoyer, M., \& L. Roudart, 2002 [1997], Histoire des agricultures du monde. Du néolithique à la crise contemporaine, s. l.: Éditions Points.

Meana, M. J., J. I. Cubero \& P. SÁez, 1998, Geopónica o extractos de Agricultura de Casiano Baso. Traducción y comentarios de M. J. Meana, J. I. Cubero y P. Sáez, Madrid: Instituto Nacional de Investigación y Tecnología Agraria y Alimentaria (INIA).

Mynors, R. A. B., 1990, Virgil, Georgics, edited with a Commentary by R. A. B. Mynors, Oxford: Oxford University Press.

$O L D=$ Oxford Latin Dictionary, ed. by P. G. W. Glare, 2 vol., Oxford: Oxford University Press, $2012^{2}$.

Ortoleva, V., 2006, "Ancora sul latino salivatvm, salivare», Hermes 134/3, 352-366.

Ortoleva, V., 2012, «Max Ihm e Eugen Oder. A proposito di alcuni autografi recentemente scoperti», Philologia Antiqua 5, 49-84.

Ortoleva, V., 2017, «Falx ueruculata e falcicula tubulata: due facce della stessa medaglia (a proposito di Colum. 2,20,3 e Pallad. 1,42,3), Commentaria Classica 4, 119-137.

Pieters, A. J., 1927, Green Manuring. Principles and Practice, New York: John Wiley \& Sons.

$\mathrm{RE}, \mathrm{F} ., 1815^{2}$, Dei letami e delle altre sostanze adoperate in Italia per migliorare $i$ terreni e del come profittarne, seconda edizione, riveduta dall'autore, Milano: Giovanni Silvestre.

Rodgers, R. H., 1975, Palladii Rutilii Tauri Aemiliani uiri inlustris Opus Agriculturae, De Veterinaria Medicina, De insitione, edidit R. H. Rodgers, Lipsiae: Teubner.

Rodgers, R. H., 2010, L. Iuni Moderati Columellae Res rustica, incerti auctoris Liber de arboribus, recognovit... R. H. Rodgers, Oxonii: Oxford University Press.

Shiel, R., 2012, "Science and Practice: The Ecology of Manure in Historical Retrospect», en: R. Jones (ed.), Manure Matters: Historical, Archaeological and Ethnographic Perspectives, Farnham-Burlington VT: Ashgate, 13-23.

$T L L=$ Thesaurus Linguae Latinae, vol. VI, pars 1, fasc. IV (1920).

VArisco, D., 2012, "Zibl and Zirāa: Coming to Terms with Manure in Arab Agriculture», en R. Jones ed., Manure Matters: Historical, Archaeological and Ethnographic Perspectives, Farnham-Burlington VT: Ashgate, 129-143.

Zohary, D., M. Hopf \& E. WeIss, 20124, Domestication of Plants in the Old World, Oxford: Oxford University Press. 